\title{
Man ser inte utställningen för bara föremål
}

TANDI AgRELL*

Title: You can't see the exhibition for the artefacts.

Abstract: Most visitors to a museum exhibition expect the presence of authentic artefacts. With their materiality and history, these artefacts are considered to be specific to the exhibition medium.

The author goes beyond this to assert that the use of authentic artefacts makes it more difficult to bring about the communication that the exhibition is trying to achieve. Despite the attempt to use it as a means of communication, the authentic artifacts in the exhibition are actually a hindrance in the communicative process.

By relating artefact-focused museum exhibitions to contemporary neo-realistic art installations, the author illustrates the role of the artefacts in the museum exhibition. The article points out how problematic the authentic artefacts are from a practical design perspective, and how the demand for authentic artefacts in the exhibition is actually a convention that limits what the exhibition can achieve as a means of communication. Key words: Exhibition design, authentic artefacts, post-structuralism, realism, fiction, relational aesthetics, content-form, phenomenology.

Att tala om upplevelsebaserade museiutställningar1 är idag ingenting konstigt, det är snarast comme il faut att skapa utställningar som rum för upplevelser numera - de flesta stora institutioner arbetar aktivt för att komma från stämpeln av dammsamlare och har de senaste 15 åren ansträngt sig för att skapa rum för upplevelser på våra museer. Liksom inom turism- och nöjesbranschen söker man locka besökare genom att erbjuda upplevelser av vår historia, man söker tala till våra sinnen och känslor, förmedla historien snarare än att undervisa om den. Samtidigt har museerna en ställning som är specifik för dem - de har att förvalta och bevara ett materiellt arv - föremål som av olika skäl anses värdefulla och betydelsebärande, nödvändiga att tas om hand för kommande generationer. Med den upplevelsebaserade strategin visas dessa föremål - insamlade, lånade, skänkta, stulna - upp på nya sätt, med syfte att berätta något, visa perspektiv, kommunicera. De flesta utställare är eniga med Eilean Hooper-Greenhill om att museiföremålen inte förmedlar någonting av sig själva, 
utan alltid förstås i en diskurs och kan läsas på ett oändligt antal sätt beroende av vem som läser dem och i vilket sammanhang. Utställarna strävar därför efter att skapa särskilda sammanhang och specifika "läsningar" med hjälp av historiska föremål.

De flesta besökare förväntar sig också att se "äkta historiska föremål” i museiutställningar. Museiföremålen anses med sin materialitet och historia vara det specifika med mediet. Ändå vill jag påstå att det är just föremålen som försvårar den förmedling man söker åstadkomma, föremålen kan trots att de används som kommunikationsmedel faktiskt hindra själva kommunikationen! I den här artikeln vill jag peka på några problem med föremålens förväntade roll i museiutställningen. Genom att relatera föremålscentrerade museiutställningar till den samtida nyrealistiska konstinstallationen vill jag belysa föremålens roll i utställningen ur ett designperspektiv och ställer mig frågan - Vad är det som faktiskt sker i den samtida museiutställningen? I det följande kommer jag dels att peka på hur problematiska museiföremålen är ur ett praktiskt designperspektiv, dels visa hur synen på föremålens roll $\mathrm{i}$ utställningen är en konvention som begränsar utställningens utsägelsesmöjligheter.

Två mycket olika utställningar utgör en fond för mina resonemang: Sápmi på Nordiska museet och Everything You Can Think of is True - the dish ran away with the spoon som visades på Det Kongelige Bibliotek i Köpenhamn under våren. Den förra är en modern, problematiserande utställning där föremålen står i centrum. Med dem vill utställarna tala om vad det innebär att vara same i Sverige idag. Sápmi är en utställning "om identitet, historia och framtid, om rättigheter och orättfärdigheter, om kulturmöten och kulturkrockar, om bilden av sig själv och bilden av den andre" ${ }^{2}-$ står det på museets hemsida. Den senare är en utställning där multikonstnären Robert Wilson - inspirerad av Alice i Underlandet - iscensätter "en verden av muligheder, fantasi og overraskelser”. Dessa utställningar är så olika och har så diametralt motsatta syften att man gärna uppfattar det som att de befinner sig i "olika ändar av skalan" - ändå, menar jag att de har mycket gemensamt - framför allt det grundläggande problem som jag ämnar diskutera. Nämligen att de inte fungerar som tänkt.

Som utställningsdesigner har även jag haft det upplevelsebaserade som riktmärke. Vi har i museivärlden sökt nya grepp och liksom museerna har jag en förhoppning om att vi ska kunna tala med besökarna i ett sinnligt konsekvent språk och hjälpa dem att vidga deras förståelse för nuet genom historiska perspektiv. Vi vill få besökarna att reflektera över vad de upplever.

\section{SÁPMI}

Vi börjar på Nordiska museet och utställningen Sápmi.

Rummet öppnar sig framför mig och jag ser en bra bit in i utställningen. Inte mycket folk, när jag är där. Skönt. Utställningen är nästan ljudlös. Jag uppfattar montrar och podier i olika höjder och formationer. Montrarnas form med sina fasade väggar noterar jag också. Liknar sarkofager? Är det meningen att jag ska tänka att föremålen ligger på lit-de-parade? Ingenting $\mathrm{i}$ den övriga utformningen tyder dock på det. Kanske används den kistlika formen inom samisk kultur? Blicken söker sig runt och stannar vid en text på en ljuslåda rakt fram. "Vems berättelse?”, läser jag. Orden på ljusskylten upprepas i olika format, i ljusare eller mörkare ton, på samiska och även på flera andra språk. Det ger intryck av en mångfald röster som talar olika starkt. Utformningen 
ger en bild av den samiska rösten som en av många i världen, samtidigt som den fyller en praktisk funktion - fler kan läsa texten. Till höger om mig visas ett bildspel som projiceras direkt på ytan av ett lågt podie, som liknar montrarna längre in i utställningsrummet. Människoporträtt och närbilder av konsthantverk avlöser varandra. Just som jag vänder mig mot projektionen visas en närbild av en blond kvinna i liggande format, med hjässan åt höger. Nästa bild visar en svart kvinna, som blir upp-och-ner-vänd i förhållande till min placering. Bilderna går varv efter varv runt podiet. Texten på podiet bredvid ger olika definitioner av termen "Urfolk".

Utställningsrummet är en av museets långsmala, säkert tio meter breda, "balkonger" högt upp i byggnaden. Fackverken i takkonstruktionen avgränsar utställningens delområden totalt sju stycken, men mitt synfält begränsas av en stor högblank svart monolit, så jag uppfattar först bara fyra delområden. Det visas film inne i monoliten och utställningen fortsätter på andra sidan. Vilken betydelse har denna blanksvarta box, förutom att möjliggöra filmvisning och fungera som rumsavskiljare? Montrarnas antal, utformning och placering medverkar till att förstärka de olika delrummen i utställningen, men utformningen ger däremot inga ledtrådar till vad dessa rum talar om. Delområdenas rubriker och övrig text är det jag har att hålla mig till. Jag rör mig från den ena montern till den andra. Läser. Tittar. Inte i någon speciell ordning eftersom rummet inte indikerar någon sådan. Montrarna innehåller olika samiska bruksföremål, men jag kan inte avgöra vilka teman som behandlas innan jag läst texten. Vad ska jag orientera mig efter? Rubrikerna är textade på en högt placerad ljuslåda som löper likt ett band genom hela lokalen. Hela utställningen hålls ihop av ljuslådan och av golvmattan (i vävt plastmaterial?), som förs upp längs montrarnas sidor och på "sittbänkar" i lokalens ena långsida. Golvmattans mönster samspelar på ett intressant sätt med ljuset i lokalen och blir till en lek med skuggor och ljusfall på montrarnas fundament, vilket emellanåt får dem att upplösas. Jag får intrycket av att utställarna vill trolla bort fundamenten för att få föremålen att framträda tydligare. Den idén förstärks av att montrarna blir belysta med hjälp av fiberoptik i form av böjda plexiglasrör. Sannolikt är det tänkt att dessa skulle vara "osynliga", men i själva verket är de mycket tydliga och ofta i vägen för föremålen.

Utställarna talar på hemsidan i starka bilder när de säger sig vilja tala om att "kulturer möts" och "kulturer krockar". Hur kommer det sig att man inte känner exempelvis den förnedring som samerna har fătt utstå och den kamp som de fortfarande utkämpar idag? Hur upplever andra svenskar i närområdet denna kamp? Det är som om själva knuten i problemet lämnas utanför och det försvårar förståelsen. Sápmi är kanske inte vad vi kallar en upplevelsebaserad utställning, men den kan inte undgå att bli just upplevelse för besökaren. Från det ögonblick jag som besökare träder in genom dörren börjar jag avsöka varje sinnlig del av utställningen efter betydelser för att försöka förstå vad utställningen vill säga. I Sápmi försvåras kommunikationen bland annat av de neutrala, enhetliga montrarna. Jag förstår dem som en sorts behållare för innehållet, som "ren" organisation. Som utställningen är utformad blir den överskådlig på så vis att den visar att den består av olika delar, men hur den är strukturerad visar sig bara i texterna. Utställningar av Sápmis typ står tydligt i vad den museologiska kritiken har beskrivit som den modernistiska traditionen där gestalt- 
ningen sträcker sig till disponering av rummet, organisering av föremålen och design av mer eller mindre stämningsskapande behållare (rummet, montrarna) för föremålen.

\section{FÖREMÅLEN SOM KOMMUNIKATIONSMEDEL}

I montern som bär rubriken Rätten till traditionell kunskap visas ett antal konsthantverksföremål. Texten berättar att traditionell kunskap bygger på praktisk erfarenhet och att den förs vidare från generation till generation. Denna praktiska kunskap som traderats av samerna i generationer (ständigt modifierad) och som var så livsnödvändig för dem kan jag bara gissa mig till. Föremålen som visas $\mathrm{i}$ montern är resultatet av en arbetsprocess som involverar samernas föreställningsvärld, tekniska kunnande och sociala värld vid en given tidpunkt och på en given plats. Jag som besökare ser inte de spår som skulle kunna antyda vilka (estetiska-etiska-tekniska) val som skaparen av föremålet har gjort under produktionen. Och ärligt talat, vem kan ens se det i de designade föremål vi umgås med till vardags $i$ vår egen kultur? Vem kan förstå de komplexa strukturer som har format en produkt, utan att först ha tillägnat sig en analysapparat och utan att ha underkastat föremålet i fråga en djupare undersökning? Jag - som utbildad designer dessutom - kan inte omedelbart avläsa dessa aspekter ur samtida föremål. Föremålen måste öppnas upp - tolkas - för att ge mening. Ändå förväntas det av mig att jag ska kunna förstå föremålen omedelbart när jag går på föremålsutställningar. Och då ställs jag inte bara inför ett föremål, utan många. Ofta väldigt många.

En monter med rubriker som Rennäringen, Rovdjuren, Renägare och renskötare och Renen presenterar mig för en stor mängd föremål, som jag förstår alla på något vis har med renskötseln att göra. Det är många vackra föremål, men de ger mig ingen föreställning om hur renskötar-situationen ser ut eller hur föremålen används i denna kontext. Kanske är det inte utställarnas intention att jag ska förstå föremålen i deras ursprungliga kontext? Jag känner igen lassot och "klämman" (till märkning av renen?), kaffepannan, en kåsa. Men resten? Vad är de för slags föremål? Hur används de? Ska jag förstå kaffepannan som specifikt samisk? Den liknar andra jag har sett, både på museum och utanför. Vad gör den specifikt samisk förutom att den har tillverkats och ägts av samer tidigare? Konstkritikern Peter Cornell erbjuder ett möjligt perspektiv. Han betraktar föremålen som konstobjekt. Kanske är det så utställarna också gör? För Cornell "så väcker sakerna [i museernas glasmontrar] förundran och häpnad och genomgår märkvärdiga mutationer; de transformeras från vanliga ting till konst". ${ }^{3}$ För honom synliggörs föremålen i kraft av att de blir presenterade på museum; de lyfts upp ur vardagen. Cornells förståelse av åskådliggörande är den institutionella konstteorins: föremålen förändras enbart i kraft av att de lyfts in i ett rum som inte är vardagens, konstens rum, eller i det här tillfället museiinstutitionen. Cornell har onekligen en poäng i att jag sällan ser de föremål som jag lever med i min vardag. De står, för att tala med Heidegger, för nära mig i mitt umgänge med dem och på samma gång för långt ifrån mig i kraft av att de "försvinner" in i livsvärldens totalitet. De är inte konceptualiserade för mig. Exempelvis framträder skeden som "sked" först om den går sönder eller jag förlorar tummen, alltså om det vanemässiga umgänget med den bryts. Då börjar jag reflektera över den. För mig framträder de historiska föremålen i Sápmi som just museiföremål - "ob- 
jekt man vanligtvis ser på museum”. Men intentionen är här att berätta mer än så. Hur väl förmår kaffepannan, bältet, repet eller skeden att berätta om vad det vill säga att vara same idag? Den tidigare nämnda skeden framträdde i förhållande till den relation som bröts och jag blev medveten om den kroppsliga kunskap jag redan hade om skeden. I Sápmi ser jag bara lösryckta föremål, jag har ingen förförståelse av dem. Har inte umgåtts med dem tidigare. Utställarna ger mig inte heller tillgång till den samiska kaffepannan som det materiella och praktiska objekt, vilket en gång hade sin självklara plats bland samer - en relation, en verklighet, som kan bli till vittnesbörd för etnologen eller arkeologen. Eftersom jag inte har någon förförståelse av den i utställningen lösryckta samiska kaffepannan, blir det svårt för mig att se den på nytt. Än svårare är det med de föremål som jag inte kan relatera till alls. Här ser jag bara objekt i deras obegriplighet. "Vad är det här? Vad kan det ha använts till? Vad vill utställarna säga mig?" Sápmi är svårtillgänglig och lättillgänglig på samma gång: den är svårtillgänglig i förståelsen av de "opaka" föremålen, men lätt att ta till sig eftersom det mesta berättandet sker i texterna.

Framvisandet av de historiska föremålen som utställningens huvudsakliga uppgift tvingar fram en utställningsform beroende av montrar, eftersom bevarandet av föremålen omgärdar dem med en rad restriktioner. I montrarna förvandlas föremålen från materiella objekt till bilder av sig själva. Eller snarare, föremålens bildmässiga sida förstärks på bekostnad av den materiella och det gör utställningen mindre sinnlig. Jag känner inte föremålens tyngd, svalka, torrhet, eller doft av trä. De är inte sinnliga för mig i utställningen; de är sinnliga i tanken. Renskeden från Sápmi är verkligen utsökt. Föreställer mig att den känns varm och len att hålla i handen, att den ligger skönt där ... Detta är något jag föreställer mig, för jag får ju inte röra vid skeden. Kanske skulle mitt intryck vara något helt annat om jag verkligen stod med föremålet i min hand? Föremålsutställningen leder till en övervikt på det diskursiva, det tänkta, och till en nedvärdering av det synliga, materiella.

\section{Everything You Can Think of IS True}

I Köpenhamn besöker jag en utställning signerad av den internationellt erkände multikonstnären Robert Wilson, Everything You Can Think of is True - the dish ran away with the spoon med undertiteln Kunstnernes skitsebøger - impressioner, ideer, visioner. ${ }^{4}$ Denna utställning tar ett helt annat formgrepp än Sápmi.

Innanför det svarta, tunga förhänget möts jag av en introduktionstext. Rummet är nästan helmörkt. Till vänster och till höger om väggen med introduktionstexten ser jag röda fläckar av ljus sväva en bit ovanför golvet. Det är fler ljusfläckar åt vänster. Jag förnimmer ljus som sipprar ut ur cirkelrunda hål i väggarna. Åt vilket håll ska jag gå? Var ska jag börja? Jag går åt höger. Det känns trögt att gå, golvet gör motstånd. Jag rör mig i ett tjockt lager av ... grus? Det knastrar (visar sig vara små, små bitar av extruderad svart plast). Dyyt ... det sfäriska ljudet avbryts och en röst hörs: "Everything you can think of is true". Rösten återkommer sedan med jämna intervaller. $\mathrm{Nu}$ börjar ögonen vänja sig vid mörkret och de röda fläckarna framträder som gung-sittytor (läste jag inte något om att gungorna används på egen risk, innan jag gick in?). Jag sätter mig. Gungar. Tar in bakgrundsljudet. Svävar. Tyngdlös. Ljudbilden är drömsk, lite skrämmande. Jag associerar till Alice i Underlandet, 
vilket inte är helt fel visar det sig när jag senare läser katalogen. Då minns jag: utställningens titel, Everything You Can Think of is True, kommer väl därifrån? Det knastrar i det gruslika och den andra personens närvaro tränger sig på med kraft. Jag ser henne knappt (vet att det är en hon, för jag går tillsammans med en kollega och vi är ensamma i lokalen). Jag följer efter och går utmed väggarna, kikar in genom de runda öppningarna. Vi ser på skissböcker av olika slag. Det är skiftande skisser, från naturalistiska porträtt i blyerts till skisser av landskap och hus. Ibland färglagda. Vissa är nedtecknade idéer, andra är registreringar av något existerande. Öppningarna följer en egen logik och inte nödvändigtvis bokuppslagens placering. Jag går från öppning till öppning (de är täckta av glas) och kommer på mig själv med att mest vara road av den beskäring som de runda fönsteröppningarna ger. Hur de ramar in mitt synfält: ibland hamnar en liten detalj i fokus, ibland är flera teckningar i blickfånget samtidigt. Andra gånger ser jag utrymmet mellan två skissböcker. Jag måste anpassa mig, vrida mig, justera min position emellanåt för att se skisserna $\mathrm{i}$ deras helhet. Det blir en rolig lek, men det tar också fokus från teckningarna. Plötsligt möter mig en tablå, en blåaktig fantasiskog i en rund öppning. Det är oväntat och gör mig förbryllad. Jag vet inte vad som väntar i nästa öppning. Lika överraskande möter jag senare öppningar med bland annat en skyltdockehand, klädd med fjärilsvingar i skimrande blågröna toner, uppstoppade kackerlackor mot en lysande grön bakgrund, en vält porslinsskål med körsbär, en kanin (även den uppstoppad). Det är vackra och suggestiva bilder, men jag förstår inte vad de betyder utöver att de ger en stämning av ett skruvat universum. Kanske - troligtvis - är utställningen full av referenser som jag inte kän- ner till. Vid några av dessa annorlunda fönsteröppningar hänger hörlurar. Tom Waits hörs i de flesta av dem, men även fågelläte (en nordamerikansk art). Vid sista öppningen: en flickröst som upprepar "Okey". Jag rör mig i en gåtfull värld. En skolklass väller plötsligt in och förtrollningen bryts fullständigt. Wilsons bräckliga universum överröstas av högljudda skrik och skratt. Alla gungar!

Jag läser i utställningskatalogen att Wilsons utställning är inspirerad av Alice $i$ Underlandet; denna fantasifulla värld full av möjligheter och märkligheter. Jag tänker att det är så utställarna uppfattar skissböckerna. Deras förståelse exponeras i rummets gestaltning, men konkurrerar med skissböckerna som uttryck för "en verden af muligheder, fantasi og overraskelser". ${ }^{5}$ Utställningskatalogen säger vidare att "udstillingsobjekt og iscenesættelse begynder at flyde sammen og fortælle en historie" ${ }^{6}$ Får utställningens iscensättning mig att fokusera på något bestämt i skissböckerna? Snarare upplever jag att de tillhör en annan värld, ett annat språk, än Wilsons drömrum. För mig blir det två parallella världar, där Wilsons starka stämningsbild överröstar föremålen. Dessa världar flyter inte samman, utan förblir åtskilda i utställningsformen.

\section{REALISM ELLER FIKTION}

De två utställningar jag har presenterat här visar på diametralt motsatta typer av kontextualisering, men jag vill hävda att de i grunden har samma problem. Båda utställningarna är hantverksmässigt välgjorda utifrån sina premisser - som inredning respektive gestaltning - men som kommunikationsmedel är de problematiska. Det råder en konflikt mellan föreställningen om de historiska föremålen som utställningens huvudsakliga material och in- 
sikten om att de måste kontextualiseras för att bli meningsfulla. Antingen är fokus på föremålen, vilka kräver kontextualisering med hjälp av texter eller andra föremål och/eller fysisk inramning för att de ska förmedla något. Frågan jag har ställt är hur pass effektiv kommunikation man uppnår med den här utställningsstrategin. Eller så är kontexten i fokus och hela utställningen blir att betrakta som ett objekt, en berättelse. I Sápmi är texterna mest betydelseskapande, föremålen behövs inte för att förstå texten. Utställarnas perspektiv blir synliggjort i texten, men inte i föremålen själva eller i relationen mellan föremål och text, det vill säga utställningen som enhet. Det är en lösning som inte förhåller sig till att utställningen upplevs i ett rum: den prioriterar intellektet. Everything You Can Think of is True är till skillnad från Sápmi en helgjuten upplevelse, där själva gestaltningen av utställningsrummet är betydelsebärande. Den skapar en berättelse utifrån utställarnas perspektiv på skissböckerna, men gör samtidigt själva föremålen överflödiga. De är inte nödvändiga för att förstå rummet.

Hur kan jag säga att dessa skilda utställningstyper har samma problem? Målet i Sápmi är att tala om ett abstrakt och komplext tema - samisk identitet - med hjälp av de äkta historiska föremålen. I Everything ... är målet att visa fram skissböcker ur museets samling. Men ingen av utställningarna integrerar de historiska föremålen i utställningsspråket på ett sätt så att de ger mening. De förblir osmälta klumpar "verklighet" i båda utställningarna. Så länge de äkta föremålen ses som utställningens självklara fokus kan formarbetet bara kretsa runt dessa. Utställningsformen kommer i princip att pendla mellan att vara rumsliga illustrerade böcker, där den mediespecifika sinnliga potentialen förblir outvecklad, eller "upplevelseutställningar" där gestaltningen tar förmedlare av den kunskap de besitter. Jag menar att vi här har att göra med en konvention, som inte längre gagnar kommunikationen.

Synen på föremålens roll i dessa utställningstyper vittnar om en annan sida av det modernistiska arvet än de sidor den museologiska kritiken har ägnat uppmärksamhet åt: det sena artonhundratalets syn på framställning - dess konstsyn. Konsten växte fram som en egen sfär, som något annat än de praktis$\mathrm{ka} /$ vardagliga och vetenskapliga sfärerna; den frigjorde sig från nyttan. Walter Benjamin talar om den speciella närvaro - auran, som konstverket (alla kulturobjekt) får genom sin historia och materialitet. ${ }^{7}$ Det historiska konstföremålet har sina rötter $\mathrm{i}$ en religiös praktik och dess huvudkvalitet är att det låter oss möta det outgrundliga, det som inte kan formuleras. Detta möte kan bara uppstå genom djup begrundan. Med sekulariseringen av konsten träder autenticiteten i kultvärdets ställe, men samlaren bevarar något av fetischdyrkan i sig, menar Benjamin. ${ }^{8}$

Andra medvetandeförmågor än det analyserande intellektet ansågs bli aktiverade i mötet med konsten. Som Robert Wilson själv säger i en intervju: "dessutom behöver inte konstnärliga uttryck betyda något". ${ }^{9}$ Det är en föreställning om att konstens uppgift är att leverera "stämningar och intryck" som i högsta grad är levande än idag..$^{10}$ För det sena artonhundratalets estetiska tänkare kunde konstverket öppnas upp genom analys, men reflektion sågs inte som möjlig i den konstnärliga processen. Det specifika med konsten, menar den svenske filosofen Hans Larsson, är att den förmår att fånga något av livets mystik - av det paradoxala hos livet - och att den gör det genom 
att finna sammanhang mellan det som är olika utan att likställa eller reducera. ${ }^{11}$

\section{FIKTION OCH REALISM}

Problemet med de äkta föremålen i utställningen är en fråga om relationen mellan verklighet och beskrivning. Konstvärlden har sedan sin frigörelse från "det upphöjda, värdefulla, formfulländade, som gav konsten dess speciella funktion inom den aristokratiska maktens system" ${ }^{12}$ sedan mitten av 1800-talet tematiserat denna relation. Med början hos Manet och impressionisterna undersöktes relationen mellan världen och betraktaren av denna. Deras konstnärliga verksamhet gav uttryck för erfarenheten av det splittrade moderna livet. De sökte skildra den borgerliga vardagen (realism) och tydliggjorde samtidigt i sin formbehandling seendet och därmed konsten som konstruktion av en bild (illusionism eller fiktion) - man utvecklade nya tekniker för framställning att ersätta det akademiska måleriets konventioner, ${ }^{13}$ man intresserade sig för hur bildens beskärning skapade ett utsnitt av omvärlden. I början av 1900-talet betonades relationen mellan konstnär och verk.

Konstens dubbelhet - som realitet och fiktion - blir tematiserad i den samtida nyrealistiska konstinstallationen och fokus har förskjutits mot en tematisering av relationen mellan verk och betraktare. Precis som museiutställningen använder sig den nyrealistiska konstinstallationen av verkliga föremål och material hämtade från livet utanför konstinstitutionen. Enligt den danska konstkritikern Anne Ring Petersen handlar realismen inte längre om att verket representerar något verkligt, utan om hur betraktaren uppfattar och förstår verket. Hon kallar det en mental och sensorisk realism. ${ }^{14}$ Det verkliga är något som utspelar sig i mötet mellan konstinstallationens fysiska framträdan och betraktaren som upplever den. Här förhandlas verkets betydelser. Konstinstallationen får sin mening både som referent till en social verklighet utanför konstrummet - genom återanvändandet av vardagliga föremål, situationer och erfarenhetsformer - och som fiktion/berättelse, men det reella är här underlagt fiktionen.

I installationens rumdannelse foregår der en kobling mellem objekter eller handlinger, der fortsætter den semiotisk og lægger pres på publikum for at få dem til at se objekterne eller handlingerne ' $i$ det andet lys', nemlig fiktionens. ${ }^{15}$

För Heidegger framträder världen i konsten; i verket synliggörs och framställs världen som både tillgänglig och dold samtidigt; den visar fram en sida, men döljer andra, och det går inte att omfatta världen i hela sin totalitet. ${ }^{16} \mathrm{Vi}$ kan inte komma åt verkligheten utanför vår språklighet, men den kan heller inte reduceras till denna. Konstinstallationen presenterar en ny verklighet (genom betraktarens aktiva deltagande) som är både föreställning och igenkännbar verklighet. Den utformas som en reflektion över något. Konkret sker det genom att sammanställa tecken, handlingar, koder, föremål från andra sammanhang med konstsfären. Nittiotalets nyrealism eller relationella konst förmår genom denna förskjutning att överbrygga de båda kategorierna "realism" och "fiktion" inom konstsfären. ${ }^{17}$ Museiutställningen är likt konstinstallationen verklig som fiktion/konstruktion, genom vilken det verkliga kan öppnas.

En intention hos konsten är ofta att uppnå ett reflektionsrum via den estetiska erfarenheten, där betraktarens förtrolighet med världen 
överskrids; där denne blir omskakad i sitt invanda sätt att förhålla sig till något verkligt. Detta reflexiva rum kräver både något igenkännbart och något främmande och att förbindelsen dem emellan inte är given. ${ }^{18}$ För att uppnå det iscensätter konstinstallationen medvetet ett spel med igenkännbara tecken från vardagssfären och konstdiskursen och med de förväntningar vi kan ha på dessa. Är det då inte så att den förförståelse jag har bara i kraft av att umgås med tingen i min egen vardag ger mig tillträde till (vissa av) de historiska föremålen? Jag kan förhålla mig till en sked, eller kosa, för att jag redan vet vad det är, och på så vis kanske kan se vad som utmärker just den samiska skeden av renben i förhållande till de industritillverkade metallskedar som ligger hemma i kökslådan. Jo, men jag behöver hjälp att se utöver det jag redan vet. I museiutställningen blir mina föreställningar inte utmanade och den reflektion vi vill uppnå går om intet.

Utställningen sitter fast i modernitetens antingen-eller-logik och pendlar mellan intellekt och känsla, innehåll och form. Antingen slår pendeln över i det ena lägret eller i det andra. Men vi vill ju förena dessa: museernas kunskaper (vetenskapliga perspektiv) ska förmedlas i ett konkret, sinnligt språk - utställningen. Den museologiska kritik ${ }^{19}$ som ser det modernistiska arvet i utställningen som hinder för förmedlingen av en ny tids perspektiv gör emellertid inte upp med den avgörande konvention som föremålens roll i utställningen utgör. Hooper-Greenhill ser dock en fara med den objektsbaserade pedagogiken, nämligen att det finns en risk att missa att "det reella" är en konstruktion. I förhållande till historiska texter anses föremålen vara en mer primär källa och med en okritisk blick på föremålen förstås de som oförmedlad verklighet, säger hon. ${ }^{20}$ Gundula Adolfsson är den i Sverige som främst har diskuterat föremålens roll i utställningssammanhang. Hon menar att man måste skilja på deras källvärde, samlingsvärde och deras utställningsvärde, men även hon menar att museiföremålens existens i utställningen är indiskutabel. ${ }^{21}$ Hon säger att de "fastmonterade objekten är för utställningen vad scenen är för teatern, en ofrånkomlig förutsättning. Men som Stanislavskij har lärt oss, kan man ändra spelstilen.”22 Föremålen är inte förhandlingsbara i utställningen. Utan dem ingen museiutställning.

Problemet ur designmässig synvinkel: laddning eller bearbetning. Kan då inte historiska föremål användas som tecken - som "realitetseffekter" ${ }^{23}$ - i museiutställningen? Frågan avgörs av hur avläsbara de är och hur de används i utställningen; hur plastiska de förmår att vara i utställningsspråket. Här menar jag att museiföremålen blir problematiska, eftersom de är källor som ska bevaras för eftervärlden och inte kan bearbetas till ett specifikt uttryck.

När föremålen "laddas" som många museologer talar om, utan annan synlig förändring än att de sammanställs med andra föremål och sätts in $\mathrm{i}$ en estetiserande ram, är det mindre troligt att dessa kommer att bli förstådda som utställarna har tänkt sig. Laddningen stannar vid det konceptuella - det tänkta. Ju mindre som visar sig konkret och materiellt i museiföremålet, desto mer krävs det av besökarens förförståelse och föreställningsförmåga. Berättelsen förblir orealiserad, åtminstone för de besökare som står utanför diskursen (oavsett om denna är etnologens eller konstnärens). Jag ifrågasätter inte den intima relation vi kan ha med föremålen i våra liv. Att vi laddar våra föremål med mening i vårt umgänge med dem. Museiutställningen är däremot en situation där vi vill samtala - i ett materiellt språk om något med andra. Man kan välja att göra 
utställningar för andra inom den egna diskursen, man måste bara vara medveten om att det är det man gör i så fall. Det ena är inte mer giltigt än det andra, men i museisammanhang, där uppdraget är att öppna upp vår historia för en allmänhet, är frågan inte oväsentlig. Hur pedagogisk behöver utställningen vara? All kunskap som ges i en utställning behöver kanske inte synliggöras? Det är inte heller möjligt. Museiutställningen behöver kanske inte säga något speciellt, utan bara ställa upp en värld av föremål, som fritt kan tolkas av besökaren? Jag menar inte att utställningens uppgift är att undervisa, men anser att den måste vara pedagogisk i meningen att vara tillgänglig. Designerns uppgift är att etablera ett språk som hjälper besökaren att gå i dialog med utställningen.

Det är besvärligt att avgöra vad som är konkret synligt och vad som är tänkt i ett uttryck. Det är inte möjligt att fastlägga. Som designer blir jag lika förblindad av min designmässiga förförståelse som arkeologen blir av sin. Svårigheten är att ensam avgöra vad i ens förståelse som är en snävare diskurs och vad som är en bredare förförståelse. Det är viktigt att kunna göra denna bedömning för att kunna avgöra hur effektivt uttrycket kommunicerar. Jag behöver gå i dialog med andra som har annan förkunskap, för att avgöra vad som är deras, min eller vår gemensamma förförståelse och därmed vad formuttrycket förmår att tala om och med vem. Om det fungerar som tänkt, med andra ord. Designerns uppgift är att utforma utställningsspråket så att det förmår att förmedla det uppdragsgivarna vill ha sagt (oftast till en större mängd människor). Det kräver bearbetning av detta materiella, sinnliga språks tecken: möjligheten att begränsa och/ eller utsträcka deras betydelser. Ett sätt att lösa problemet kan exempelvis vara att använda loppisfynd som kan be- arbetas. I en äldre bibel klistrade jag i ett projekt in en sida med citat från 1920-talets arkitekter och samhällsplanerare som dikterade hur människor borde leva i sina lägenheter om ett rum och kök. ${ }^{24}$ Bibeln låg uppslagen på ett sängskåp i formen av ett altare, ett "släktens altare"; en centralt placerad mormorsklocka hängde på väggen med familjefotografier runt om. Frågan är vilka tecken som krävs och hur mycket som behöver uttryckas explicit för att sätta besökaren på spåret av berättelsen. Hur får man besökaren att rikta uppmärksamheten mot något bestämt?

Det finns onekligen en poäng $i$ att samla in och bevara föremålen - den tröghet som de erbjuder, gör att det inte går att konstruera vilka som helst sanningar om dem, även om de kan förstås på otaliga vis. Men samlandet och det vetenskapliga arbetet med museiföremålen får inte förväxlas med framställningen av kunskapen om vår historia; de berättelser museet vill ge vidare. Museiföremålen är inte samma sak som de föreställningar vi kan ha om dem och min poäng är att vår (outtömliga) förståelse av dem är nya ting som kräver sina gestalter. Det är dessa gestalter som ska materialiseras i utställningen, menar jag. Kanske är det möjligt att, liksom filmen frigjorde bilden från det kultiska, ${ }^{25}$ låta utställningen som fiktion ${ }^{26}$ lösgöra det materiella och det historiska från föremålen, för att återförena dem i en ny enhet, där "discursive formation intersects with material properties". ${ }^{27}$

\section{UTSTÄLLNINGEN SOM ETT OBJEKT}

Utställningen måste alltså förstås som en enhet, där diskurs och materialitet integreras. Som komplext objekt ska det fås att kommunicera med besökaren som kulturell varelse och som kropp. I den nyrealistiska konstinstallationen 
medtänker konstnären betraktarens rörelsemönster genom att planera för möjliga vägar genom verket och betraktaren inbjuds till fysisk och/eller andlig prövning. ${ }^{28}$ För att förstå den nyrealistiska konstinstallationen måste betraktaren involvera sig i den genom faktiska kroppsliga handlingar. Ring Petersen talar om detta som en "koreograferet bevægelse, der indgår i en betydningsskabende proces", ${ }^{29}$

I Sápmi har ett av delrummen designats för att kunna läsas från två håll. Montrarna står med långsidan mot de två huvudsakliga gångriktningarna och på var sin sida om glaskuporna som skyddar föremålen är en text placerad. Det är samma text, men vänd åt olika håll så att den kan läsas från båda riktningarna. Den första av dessa montrar som jag möter innehåller en mängd mindre figurer: samer och renar. De står med ryggen till. Jag kan dock inte utläsa någon mening med att möta dessa figurer bakifrån, det framstår mer som en tillfällighet. Den här typen av konflikter i utställningsspråket som handlar om hur man har tänkt gångmöjligheter är vanliga i museiutställningar. Troligtvis har utställarna inte velat styra besökarna, utan vill låta dem själva bestämma. Men en viktig fråga är hur mycket vi ska lämna över till besökarna och hur mycket vi ska styra besökarnas uppmärksamhet. Designern måste kunna tänka sig in i hur besökaren kommer att förhålla sig till utställningsrummet och röra sig genom det: om besökaren står på en given plats i utställningen, vad kommer denne då troligen att orientera sig efter? Ett ljud som lockar bakom en vägg helt nära? En belyst trafikskylt, som strålar intensivt röd längre in i rummet? Den lilla filmade sekvensen - knappt synbar nere vid golvlisten - vars minimala rörelse aktiverar rummet? Hur vill vi att besökaren ska orientera sig? Designern måste kunna se om utformningen gör att något lätt förbigås eller om det kom- mer att dominera rummet, för att kunna etablera ett språk som hjälper besökaren att gå i dialog med utställningen.

Det finns ingen på förhand given förbindelse mellan ett utställningstema och det utställningsmaterial som ska gestalta detta. Det finns inte en formlösning, lika lite som ett svar på hur vi ska se på vår historia, utan det specifika med utställningssituationen är att den är komplex och inte fullt ut överblickbar: variationsmöjligheterna är enorma och detta gör bearbetningen nödvändig. Det krävs en viss frihet att kunna pröva olika (form)möjligheter - vilken mening ges? Får vi sagt det vi vill säga? Osäkerhetsmomentet - möjligheten att ta nya vägar - finns med hela vägen. Detta gäller all framställning, även den vetenskapliga som framställer sin kunskap om världen i rapporter, essäer och i seminarieform. Det är svårt att föreställa sig en akademisk rapport med en kontextualiserande inledning och i övrigt sida upp och sida ner med avbildade föremål till fri disposition att tolka för läsaren. Eventuellt med någon faktuell text här och var. Föremålen måste tolkas av någon och tolkningen måste förhållas till tidigare kunskap. En rapport utan presentation av forskningsstrategi och argumentation för ett resultat (det vill säga utan berättelse) kommunicerar inte bara dåligt, den är ogjord. En utställning som inte aktivt förhåller sig till att den är en konstruerad berättelse som upplevs i ett rum, är på samma sätt ogjord - inte realiserad.

\section{ÖPPEN OCH KOMPLEX FRAMSTÄLLNING}

Everything ... är en tydligt konstruerad berättelse, som upplevs som en enhet, men som objekt blir den lika opak som föremålen i Sápmi. Hur kan man tänka sig den nya utställningsenhetens form? Konstnären skapar med 
hjälp av sin intuition, enligt Hans Larsson, och denna är en förmåga att fånga en komplex verklighet i en enda bild - en helgjuten, avslutad form. Den verkar just genom att inte göra medvetna estetiska och etiska val. Den är motsatsen till det analytiska tänkandet. Donald A. Schön ser däremot reflexivitet som en grundläggande betingelse för all praktisk verksamhet, så även framställandet. Designprocessen blir hos honom en komplex situation; tolkningsrörelsen mellan designern och dennes material ses som analog med den mellan verk och betraktare (eller etnolog och föremål). Man måste välja väg, göra överväganden och varje (val)situation rymmer både det man gör av vana utan att tänka över det - det hemtama i skissandet, vilket både begränsar processen och ger den stabilitet, och det reflexiva - det som ger den kreativa öppningen till nya möjligheter. ${ }^{30}$

Designprocessens ögonblick av öppenhet i samtalet med materialet är en översedd potential i utställningsproduktionen. I ett utställningsprojekt undersökte vi moderniseringen av Sverige genom bostaden som metafor. Vardagsrummets tredje del - postmodern tid inleddes med ett stiliserat vitrinskåp bakom vilket låg en stor ryamatta varpå krigsbilder från Vietnam projicerades. Inifrån vitrinen hördes Sonja Åkessons läsa sin dikt "Jag bor i Sverige" som känslomässigt avstängd hemmafru. Ryamattan utarbetades som en konkretion av metaforen "att få in hela världen på mattan", en bild av tv-mediets genomslagskraft, vilket förändrade vårt sätt att använda vardagsrummet. Det skulle vara en mjuk och ombonad matta och jag valde ryamattan för att den signalerade "hög mysfaktor i familjens sköte". Krigsbilderna var svartvita reportagebilder ur SVT:s arkiv och de projicerades utan ljud. Krigsbilderna fungerade väl ihop med
Sonja Åkesson, men något inträffade som jag inte hade kunnat förutse. Mattans tjocka garnhår såg ut som kraftiga penselstråk i mötet med den projicerade filmen. Ryamattan "försvann" och blev ett mellanting mellan skärm och målning. Effekten var fascinerande, men den förändrade också den bild jag ville få fram. Hade jag haft mer tid skulle nästa steg ha varit att fråga om denna effekt var önskad, om den tillförde mattan som utsaga något. Vilka andra matt-material skulle ge vilka betydelser? Som idé fungerade mötet mellan ryamattan som tecken för det ombonade hemmet och reportagebilderna som tecken för tvrutans chockerande förmedling av Vietnamkriget, men helt oförutsägbart hade ett nytt uttryck skapats när idén skulle realiseras. Bilden var inte färdigtänkt $\mathrm{i}$ och med den första realiseringen; genom att pröva mig fram hade mattans uttryck kunnat preciseras och fördjupas. Som designer bearbetar man alltid ett material som "svarar igen" med ny betydelse i Schöns mening, ${ }^{31}$ men den här situationen tydliggjorde konkretiseringen som en del av det konceptuellt-reflexiva arbetet. Det blev en ögonöppnare för mig: realiseringen är betydelseskapande och inte bara ett sätt att (tekniskt) söka sig mot ett givet uttryck. Framställande kan inte ske utan ett samtidigt tolkande, att skapa är samtidigt att förstå.

Med vår nya konstgjorda eller fiktiva blick, blir det möjligt att tränga djupare in i det verkliga, genom att vi väljer att fokusera på vissa aspekter och göra dessa åtkomliga för en vidare undersökning, säger Benjamin. Den föremålscentrerade utställningens enklare form för framställning hindrar museologerna att nå djupare i sin egen förståelse av vad de vill säga och det hindrar även designerns möjligheter att gestalta denna förståelse. ${ }^{32}$ Benjamin fortsätter: valen blir en del av uttrycket eller formen, när 
vi lär oss bemästra konstens nya teknologiska villkor. Han jämför teatern med filmandets sönderdelande av världen i en mångfald fragment, vilka sedan sätts samman till en ny värld - filmen. Genom en skicklig användning av mediet kan magin uppstå igen. ${ }^{33}$ I den nya tidens estetik blir valen möjliga att följa: konsten och vetenskapen sammanfaller (i en komplex, öppen och oavslutad framställning).

\section{NY VÄG}

Föreställningen om att museiutställningens berättigande ligger $\mathrm{i}$ att visa fram föremål ur samlingarna är en konvention som lägger allvarliga hinder i vägen för mediets utveckling. Med stöd i ett fenomenologiskt perspektiv menar jag att den förståelse av de museala föremålen som ska förmedlas inte visar sig i utställningen. Föreställningen av föremålen får inte förväxlas med sakerna själva. Det är tolkningen som ska ges ny form och materialitet. Diskurs och materialitet måste frigöras från museiföremålen och ses som aspekter av den enhet utställningen utgör - utställningen är självt ett objekt. Detta objekt är en sinnlig värld som besökaren går in i och tolkar. Man kan inte räkna med att besökaren delar museologernas diskurs och utställningar som inte erkänner detta problem blir krävande för den oinvigde besökaren. ${ }^{34}$ Avståndet mellan besökaren och museets pedagogiska strävan att öppna upp vår historia blir längre i den traditionella utställningsformen där föremålen är $\mathrm{i}$ centrum, än i det fiktiva-konstnärliga perspektivet. ${ }^{35}$ Kommunikationen blir mindre effektiv, uppnår inte sitt syfte helt enkelt. Föreställningen om att det är museiföremålen i utställningen som gör den verklig får snarare motsatt effekt. I det som verkligen framträder bryter förbindelsen samman mellan utställ- ningen som kommunikationsform och den verklighet man vill framställa; utställningen blir nostalgisk och mystisk. För att få utställningar att i högre grad vara verkliga, både som konkreta uttryck och som sannare i förhållande till den verklighet de vill tala om, måste utställningen först erkännas som fiktionsrealitet.

Museiutställningen behöver frigöra sig och lära känna sig själv som medium på samma sätt som konsten gjorde det på artonhundratalet. Den måste förstås utifrån sin position mellan vetenskap och rumslig framställning för att utnyttja sin fulla potential som konceptuellt och sinnligt medium. Om utställningen frigörs från museiföremålens begränsning av uttrycket, skulle den få möjlighet att finna sin form på nytt, från en utställningsform med rötterna i artonhundratalets epistem, till ett samtida medium. Utställningen skulle (kunna) bli långt mer konkret och materiell än den är idag; material som jord, mögel med mera skulle kunna föras in i museernas rum ... om det gav mening i förhållande till det man ville berätta.

Detta utställningsperspektiv innebär onekligen en sorts fortsättning av det moderna synliggörandet. Tar jag död på det magiska med utställningen genom de krav jag ställer? Det är sällan jag upplever de magiska ögonblick med museiföremålen som Cornell talar om. Jag saknar inte känsla för intensiteten - det som drar till sig min uppmärksamhet (det som tidigare kallades vackert?). Till exempel den röda bokens glöd när den fångar upp en osynlig solstråle som letat sig in i bokhyllan. Den lilla kompakta röda boken träder fram emot mig, lösgör sig från bokmassan och väcker ett begär i mig. Eller i matsalsbordets vibrerande kant som uppstår i det illusoriska mötet med de såpade golvtiljorna. Det något dunkla varma ljuset väcker linjen till liv. Men museiutställningen "trollbinder" mig inte, den är inte 
magisk för mig i meningen att den väcker förundran och förbinder mig med världen, men väl mystifierande $\mathrm{i}$ meningen att den inte är särskilt effektfull som kommunikationsform. Däremot tror jag att det är möjligt för magin att uppstå genom en utställningsform som till sin karaktär är oavslutad och komplex. Den skulle kunna ge det där suset, få oss att häpna och att entusiasmeras. Den skulle kunna ge oss nya perspektiv på vår verklighet.

\section{NOTER}

1. Jag talar om utställningar med kulturhistoriskt perspektiv och som produceras av museer. Utställningarna kan antingen visas på ett museum eller ta plats på andra lokaliteter.

2. http://www.nordiskamuseet.se/Publication.asp? publicationid $=9864 \&$ topmenu $=148$.

3. Cornell, Peter: Saker - Om tingens synlighet. Hedemora: Gidlunds 1997, s. 10.

4. Visades på Det Danske Kongelige Bibliotek/Den Sorte Diamant 3 dec 2008-4 apr 2009.

5. Everything You Can Think of is True - the dish ran away with the spoon, udstillingstekster, kunstnernes skitsebøger - impressioner, ideer, visioner. København: Det Kongelige Bibliotek, 2008, s. 12.

6. Ibid., s. 13.

7. Walter Benjamin: "Kunstværket i dets tekniske reproducerbarheds tidsalder". Kultur og Klasse 77. No 1 Årg 22, 1994:15-42. Översättning: Jørgen Holmgaard, s. 16-17.

8. Ibid., s. 37.

9. Lotta Jonsson, "Regisserad design". Form 1/01, s. 47.

10. Ibid., s. 40 och s. 43.

11. Larsson, Hans: Intuition: Nagra ord om diktning och vetenskap. Stockholm 1997 (1892), s. 19-21.

12. Rune Gade: "Readymade-realisme. Noget om det 'gamle' ved den 'nye' realisme". I Virkelighed, virkelighed! - Avantgarden realisme. Red. Karin Petersen, Mette Sandbye. København 2003, s. 222. Rune Gade citerar här den belgiske konstprofessorn Thierry de Duve.

13. Ett hantverk för det klassiskt sköna, som ansågs behöva återupprättas i den nya moderna förflackningens tid.

14. Anne Ring Petersen: "Realisme, teatralitet, ritual. Aspekter af installationens æstetik”. I Reality Check. Red. Marianne Torp et al. København: Statens Museum for Kunst, 2008, s. 46.

15. Ibid., s. 57.

16. Heidegger, Martin: Konstverkets ursprung. Göteborg: Daidalos 2005. Översättning: Sven-Olov Wallenstein, s. 72-80.

17. Det historiska avantgardet (1910-20-tal) försökte överskrida gränsen mellan konst och verklighet, men lyckades i sina försök snarare visa på konstens karaktär som språk, som konvention. Konsten som särskild kategori blev förstärkt. I den relationella estetiken överskrids gränsen, utan att upplösas. Den blir snarare porös.

18. Ring Petersen, 2008, s. 59.

19. Gundula Adolfsson, Eilean Hooper-Greenhill, Camilla Mordhorst och Kitte Wagner.

20. Hooper-Greenhill, Eilean: Museums and the Interpretation of Visual Culture. London 2000, s. 106.

21. Adolfsson, Gundula: Människa och objekt i smyckeskrin - en analys av arkeologiska utställningar i Sverige. Lund: Symposium Bokförlag \& Tryckeri AB 1987, s. 76-77.

22. Adolfsson, 1987 , s. 35 .

23. Rune Gade: "Looking for a Husband with a EU Passport". Passepartout. No 22 Årg 11, 2003, s. 65. Artikel om den jugoslavienfödda konstnären Tanja Ostojics projekt med samma namn. Ostojic iscensätter ett spel med tecken från den sociala diskursen och konstdiskursen och det verkliga blir till "realitetseffekter" i den fiktion hon skapar.

24. Råden "ovanifrån” var att använda rummet, is- 
tället för låta det vara ett nästan oanvänt högtidsrum - finrum - och leva i köket. Från en utställning om moderniseringen av Sverige sedd genom bostaden. Utställningen Tid på H99 i Helsingborg.

25. Benjamin, s. 23-24.

26. Förstått som de betydelser som utställningens fysiska uttryck aktiverar/aktiveras i mötet med besökarna.

27. Hooper-Greenhill, s. 103. Hon talar om objekt som platser där det diskursiva genomkorsar det materiella. Jag konstaterar att utställningen i sig också är ett objekt.

28. Ring Petersen, 2008, s. 54-55.

29. Ring Petersen, 2008, s. 52.

30. Schön, Donald A.: The Reflective Practitioner: How Professionals Think in Action. New York 1983. s. 49-69, 76-104, 275-283.

31. Schön, 1983, s. 94.

32. En mer komplex utställningsstrategi är att låta museiföremålen möta varandra (eller samtida föremål) i oväntade sammanställningar. För att få syn på detta mötes betydelser, krävs att de enskilda föremålen fungerar som tydliga tecken. Då kan ett reflexivt "mellanrum" uppstå, men det ställer ännu högre krav på besökaren att dela utställarnas diskurs. Strategin liknar designerns sätt att generera nya former ur ett material. Jag föreställer mig att det kan vara en produktiv metod vid tolkningen av föremålen också.

33. Ett bemästrande som samtidigt innebär en anpassning till tekniken.

34. Inte heller inom en diskurs ges meningen med föremålen direkt, även om det kan upplevas så när man har uppnått en viss erfarenhet och blivit hemmablind. Meningen förhandlas mellan de synliga tecknen och någons perspektiv.

35. Avstånd till dåtidens eller andra platsers människor och föremålens livsvärld, men även mellan utställare och besökare i nutid.

\section{REFERENCER}

\section{Bøger:}

Adolfsson, Gundula: Människa och objekt i smyckeskrin - en analys av arkeologiska utställningar i Sverige. Lund: Symposium Bokförlag \& Tryckeri AB 1987.

Cornell, Peter: Saker - Om tingens synlighet. Hedemora: Gidlunds 1997.

Heidegger, Martin: Konstverkets ursprung. Göteborg: Daidalos 2005, översättning: Sven-Olov Wallenstein.

Hooper-Greenhill, Eilean: Museums and the Interpretation of Visual Culture. London 2000.

Larsson, Hans: Intuition: Nagra ord om diktning och vetenskap. Stockholm 1997 (1892).

Schön, Donald A.: The Reflective Practitioner: How Professionals Think in Action. New York 1983.

\section{Artiklar, kataloger, hemsidor:}

Anne Ring Petersen: "Realisme, teatralitet, ritual. Aspekter af installationens æstetik”. Reality Check. Red. Marianne Torp et al. København: Statens Museum for Kunst, 2008.

Everything You Can Think of is True - the dish ran away with the spoon, udstillingstekster, kunstnernes skitsebøger - impressioner, ideer, visioner. København: Det Kongelige Bibliotek, 2008.

Lotta Jonsson: "Regisserad design". Form 1/01.

Rune Gade: "Looking for a Husband with a EU Passport". Passepartout. No 22 Årg 11, 2003.

Rune Gade: "Readymade-realisme. Noget om det 'gamle' ved den 'nye' realisme". Virkelighed, virkelighed! - Avantgarden realisme. Red. Karin Petersen, Mette Sandbye. København 2003.

Walter Benjamin: "Kunstværket i dets tekniske reproducerbarheds tidsalder". Kultur og Klasse 77 . No 1 Årg 22, 1994:15-42, översättning: Jørgen Holmgaard .

http://www.nordiskamuseet.se/Publication.asp?publicationid=9864\&topmenu=148, 2009.08.03 kl 15.30 . 
TANDI AgRell

$44 \quad$ *Tandi Agrell tog examen som inredningsarkitekt frän Danmarks Designskole i København 1996. Hon har arbetat som frilansande utställningsdesigner i flera ar, bland annat med Helsingborgs Museum, Malmö Kulturmiljö och Mångkulturellt Centrum. Tandi Agrell har en Fil mag i Praktisk kunskap (Södertörns Högskola 2009). Därutöver har hon läst idéhistoria (Göteborgs universitet 1993-94) och modern kulturhistoria (Abent universitet, København, 2003-04). Denna artikel är en bearbetning av delar av hennes magisteruppsats $i$ praktisk kunskap, som blev färdigställd $i$ juni $i$ àr.

Adresse: Spacing designstudio, clo Kolonien, Telefonvägen 30, SE-126 37 Hägersten

E-mail: tandi@spacing-design.se 